\title{
GMR
}

\section{Evaluation of grain yield in sorghum hybrids under water stress}

\author{
C.B. Menezes ${ }^{1}$, D.C. Saldanha², C.V. Santos ${ }^{3}$, L.C. Andrade ${ }^{3}$, M.P. Mingote Júlio ${ }^{3}$, \\ A.F. Portugal ${ }^{1}$ and F.D. Tardin ${ }^{1}$ \\ ${ }^{1}$ Embrapa Milho e Sorgo, Sete Lagoas, MG, Brasil \\ ${ }^{2}$ Unifemm, Sete Lagoas, MG, Brasil \\ ${ }^{3}$ Universidade Federal de São João Del-Rei, Sete Lagoas, MG, Brasil \\ Corresponding author: C.B. Menezes \\ E-mail: cicero.menezes@embrapa.br \\ Genet. Mol. Res. 14 (4): 12675-12683 (2015) \\ Received March 16, 2015 \\ Accepted July 14, 2015 \\ Published October 19, 2015 \\ DOI http://dx.doi.org/10.4238/2015.October.19.11
}

\begin{abstract}
Sorghum grain yield can be significantly affected by climatic changes, especially drought and high temperature. The purpose of this study was to evaluate hybrids of grain sorghum grown under normal irrigation conditions or water stress in order to select those likely to be more tolerant of drought. Forty-nine hybrids were grown in a randomized block design experiment, with three replications. The plots consisted of four rows of $5 \mathrm{~m}$ length. Grain yield, weight of 1000 grains, harvest index, days to flowering, and plant height were measured. All of these characteristics were affected by water stress; however, grain yield showed the largest relative reduction. Comparison of the various genotypes showed that some hybrids had an acceptable grain yield under water stress, and maintained a high average yield compared to growth without stress. Several hybrids gave better grain yield than commercial check cultivars: 1170090, 1170092, 1170064, 1167026, 1167064, 1170093, 1167008, 1167029, 0009061, 1167092, 1105647, and 1170019 stood out for their acceptable plant height, earliness, and higher productivity.
\end{abstract}

Key words: Sorghum bicolor; Abiotic stress; Drought tolerance; Plant breeding 


\section{INTRODUCTION}

Climate change has emerged as an obstacle to the development of agriculture worldwide. Changes in temperature, amount of carbon dioxide $\left(\mathrm{CO}_{2}\right)$, and the frequency and intensity of extreme weather, such as floods and drought, have had significant impacts on crop yields. Drought is an important environmental factor affecting the productivity of crops. Climate change models predict greater variability in rainfall patterns with increased periods of summer drought that will affect many regions, including Brazil (IPCC, 2012).

Climate change is likely to affect food production in each of the five Brazilian federations differently. It has been estimated that by 2030, the country could lose about 11 million hectares of land suitable for agriculture because of climate change. To achieve national development, food security, adaptation to and mitigation of climate change, as well as other economic goals in the coming decades, Brazil will need to increase significantly the yield per area of cultivation of food and pasture systems, while at the same time reducing deforestation and rehabilitating millions of hectares of degraded land (PBMC, 2013).

Worldwide, drought is perhaps the most important abiotic stress limiting crop productivity. The effects of drought can be mitigated through plant breeding to create cultivars adapted to new climatic conditions and resistant to evolving pests and diseases. Drought tolerant crops, such as sorghum, need to be better exploited to reduce the impact of climate change.

In addition to its drought tolerance, sorghum can also withstand wet extremes better than many other cereal crops, especially maize. Sorghum continues to grow, although not well, in flooded conditions; maize, by contrast, will die. Additionally, sorghum can produce grain even when temperatures are high (Reddy et. al., 2011).

Sorghum is the fifth most important grain crop in the world, and the primary food source for people in many developing countries. The area planted to grain sorghum in Brazil has increased in the last decades. The major production areas are in the South East region, in the states of Goiás, Mato Grosso, and Minas Gerais. Even though the national average yield is 2.7 tonnes/ha (CONAB, 2015), results of experimental trials indicate that this yield can be doubled if growers improve their crop management using available strategies.

Sorghum yields have failed to increase or have even declined because production has been pushed to marginal areas and poorer soils. In Brazil, sorghum has been grown as a succession crop, i.e., second season, after soybean. After harvesting the soybean, the farmer begins sowing corn in late January and early February. This period of sowing increases the risk of crop failure or of reduced crop yield due to the increased likelihood of drought stress. In most cases, the sorghum is sown without any fertilizer.

This winter season in Brazil is characterized by erratic, poorly distributed, and inadequate rainfall. The rains often have a normal start but terminate prematurely, thereby exposing the crop to post-flowering stress. In other years, the rainy season may start normally but may stop temporarily for two to three weeks after seedling emergence, thereby exposing the young seedlings to early season (pre-flowering) stress.

Three growth stages have been identified in sorghum that are critical for the response to drought: GS1, seedling establishment (early vegetative stage); GS2, pre-flowering (panicle differentiation to flowering); and GS3, post-flowering (grain fill to physiological maturity of grain). Two distinct types of drought stress response have been identified and are related to GS2 and GS3. Plants under stress at GS2 exhibit a pre-flowering response that directly affects panicle size, 
grain number, and grain yield. Under GS3 stress, premature plant death, increased susceptibility to charcoal rot, stalk collapse and lodging, and a significant reduction in seed size may occur; each of these can result in decreased yield (Rosenow et al., 1996; Magalhães et al., 2003; Tolk et al., 2013; Borrell et al., 2014).

In Brazil, post-flowering stress is more frequent, and identification of tolerant germplasms will be important for the future development of this crop. The objective of this study was to compare the yields of sorghum hybrids grown under post-flowering drought stress and without water stress.

\section{MATERIAL AND METHODS}

Trials were carried at the Experimental Station of the Gorutuba in Nova Porteirinha, MG, Brazil, located at latitude $15^{\circ} 47^{\prime} \mathrm{S}$, longitude $43^{\circ} 18^{\prime} \mathrm{W}$ and $516 \mathrm{~m}$ above sea level. The climate of this region is semi-arid, with regular rainfall; it is therefore a representative region for drought tolerance tests. Rainfall in Nova Porteirinha occurs principally from November to March with a welldefined dry season between May and October. The maximum and minimum temperatures during the trials are shown in Figure 1. No rain was registered during the period of the trials.

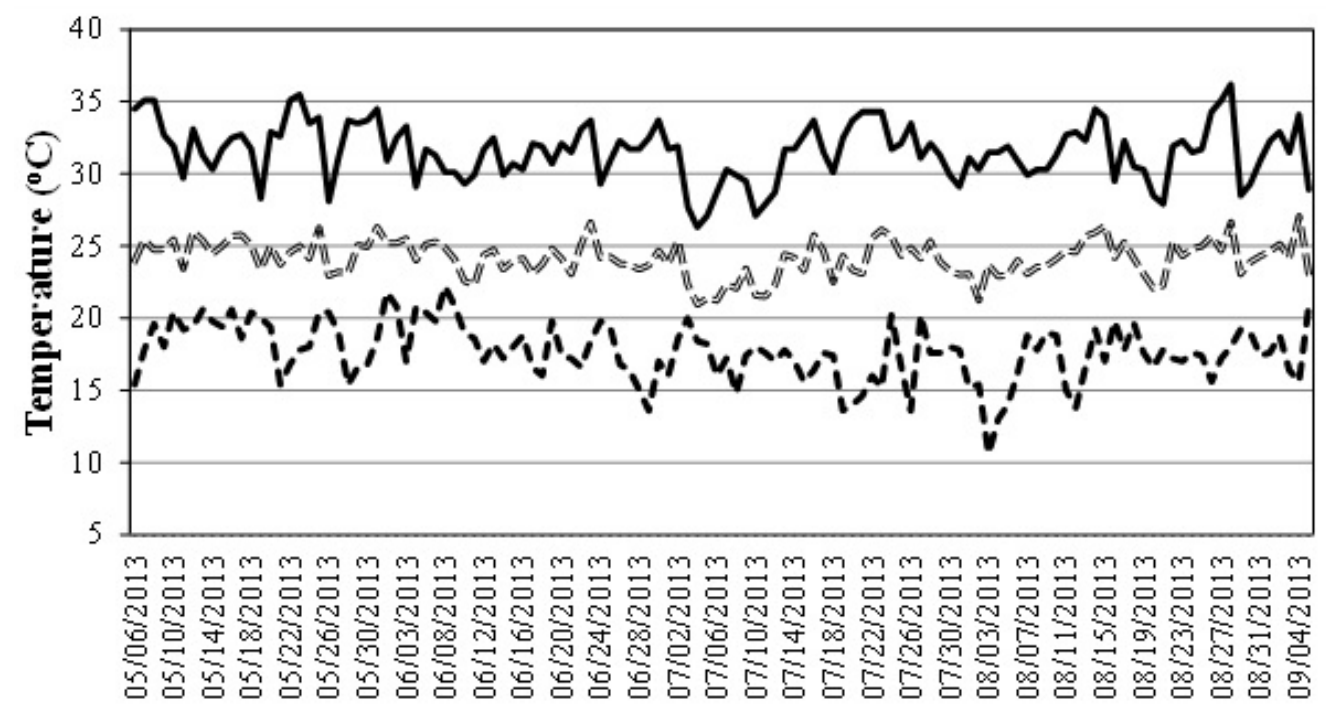

—Max. Temp. - -- Min. Temp. = =- Mean Temp

Figure 1. Mean, maximum and mininum air temperatures during the trial period at Nova Porteirinha, 2014. Source: Instituto Nacional de Meteorologia.

Forty-nine sorghum hybrids were evaluated: 43 were experimental hybrids and six commercial check cultivars (BR 304, BRS 310, BRS 330, BRS 332, DKB 550, and 1G282). The experiments were initiated on May 6, 2013. For plants grown without water stress, irrigation was performed until the complete filling of the grains. Water stress conditions were achieved by interrupting the irrigation at around 45 days after planting (June 20,2013) when most of the plants were at the booting stage (i.e., just prior to flowering). 
An experimental design of randomized complete blocks was used, with three replicate blocks and plots of four rows of $5 \mathrm{~m}$ length and $0.5 \mathrm{~m}$ between rows. The two central rows of each plot were harvested. Sowing was carried out with excess seeds and, after thinning at 30 days, the plant density was 200,000 plants/ha. The water-stress environment was located $18 \mathrm{~m}$ from the stress-free environment to prevent any interference between the two treatments. Starter fertilizers were applied using $200 \mathrm{~kg} / \mathrm{ha}$ of formulated fertilizer 08-28-16 (N-P-K) + Zn. At 30 days after sowing, $100 \mathrm{~kg}$ urea was side-dressed in the area.

Weeds were controlled with atrazine (2-chloro-4-ethylamine-6-isopropylamine-s-triazine) at $3.0 \mathrm{~kg} / \mathrm{ha}$, and hand hoeing was used as needed to control weeds during the study.

The following characteristics were measured: grain yield, days to flowering, plant height, weight of 1000 grains, and harvest index (HI). Yield was obtained by weighing the grain mass, corrected to $13 \%$ moisture, transforming the results to tonnes/ha. Days to flowering was estimated by counting the number of days between sowing and the moment when more than $50 \%$ of the plants in a plot achieved anthesis. The height of the plants was obtained by measuring the distance between the ground and the apex of the panicle at time of physiological grain ripeness. The weight of 1000 grains was obtained from two samples of grains taken randomly. The HI was the ratio of grain weight to total weight of the panicle.

Statistical analyses were performed using the Genes software (Cruz, 2006), and the Scott \& Knott test was used to group the hybrids.

\section{RESULTS AND DISCUSSION}

There were significant differences between the sources of variation for hybrids and environments for all traits. The results show that the hybrids performed differently under the two water regimes (Table 1). A reduction in grain yield under stress conditions was expected as stress reduces the translocation of photoassimilates to the grains, resulting in smaller and fewer grains. The interaction genotypes $x$ environments was significant only for grain yield and HI. Grain yield and weight of 1000 grains decreased 47 and $18 \%$, respectively, under drought stress compared to non-stressed condition (Table 1). Our analysis indicates that although sorghum is relatively drought tolerant, it still needs a minimum soil moisture to develop a good grain yield. The drop in grain yield could not be explained only by the loss in grain weight, which accounted for less than half of the total reduction. We suspect that the water stress also reduced the number of grains per plant, probably due to an adverse effect on flower fertilization.

Table 1. Joint analyses of variances for grain yield, days to flowering, plant height, weight of 1000 grains (W1000), and harvest index $(\mathrm{HI})$, in the 49 sorghum hybrids grown with and without water stress.

\begin{tabular}{|c|c|c|c|c|c|c|}
\hline \multirow[t]{2}{*}{ Source of variation } & \multirow[t]{2}{*}{ d.f. } & \multicolumn{5}{|c|}{ Mean squares } \\
\hline & & Yield (t/ha) & Flowering (days) & Height $(\mathrm{cm})$ & W1000 (g) & $\mathrm{HI}$ \\
\hline Replication & 4 & 10.23 & 7.09 & 2239.58 & 184.29 & 0.067 \\
\hline Hybrids (H) & 48 & $3.09^{* *}$ & $30.25^{\star *}$ & $957.51^{* *}$ & $57.99^{* *}$ & $0.012^{\star \star}$ \\
\hline Environments (E) & 1 & $580.20^{\star *}$ & $102.98^{\star \star}$ & $64362.24^{\star *}$ & $1432.26^{\star \star}$ & $0.460^{* *}$ \\
\hline$H^{*} E$ & 48 & $1.18^{* *}$ & $1.12^{\mathrm{ns}}$ & $147.84^{\mathrm{ns}}$ & $21.95^{\text {ns }}$ & $0.005^{\star *}$ \\
\hline Error & 192 & 0.59 & 0.97 & 104.99 & 26.52 & $0.003^{*}$ \\
\hline Mean NS ${ }^{1}$ & & 5.98 & 65.24 & 150.02 & 24.72 & 0.66 \\
\hline Mean WS² & & 3.17 & 64.06 & 120.43 & 20.31 & 0.58 \\
\hline CV (\%) & & 16.72 & 1.52 & 7.58 & 22.87 & 8.38 \\
\hline
\end{tabular}

**,* Significant by F-test at 1 and $5 \%$ levels of probability, respectively. ${ }^{\text {ns Non significant. }{ }^{1} \text { No stress environment. }{ }^{2} \text { Water }}$ stress. 
Reductions in sorghum grain yield due to drought stress before anthesis are related to decreases in grain number, while a smaller grain size is responsible for yield losses when water deficits occur after anthesis (Mutava, 2011). Manjarrez-Sandoval et al. (1989) found that drought stress during anthesis caused a $31 \%$ reduction in grain number per head while grain size remained constant, so the loss in grain yield per panicle was about 36\%. Menezes et al. (2014) found that drought stress significantly affected the yield of sorghum lines, causing a reduction of $43 \%$ compared to the full-irrigation condition.

The average Brazilian sorghum productivity is currently 2.7 tonnes/h (CONAB, 2015). This is low compared to other sorghum-producing countries such as the United States and Mexico, but similar to countries such as Burkina Faso and Nigeria. The low productivity of sorghum in these countries may be the result of sowing the crop at the end of the summer rainfall. The selection of hybrids with greater tolerance of drought should contribute to an increase in national productivity, enabling a more profitable second season crop.

Despite the reduction in irrigation being timed to just prior to flowering, we still identified the influence of stress on days to flowering and plant height, with reductions of 2 and $20 \%$, respectively (Table 1 ). Although there was only a small difference in flowering time between the two treatment groups (1.18 days), this was found to be significant in the ANOVA $(P<0.01)$. This result indicates that stopping irrigation 45 days after planting promoted water stress before anthesis in some hybrids and not afterward, as was desired. The significant difference might also be a consequence of differences in the timing of maturation in the various hybrids. Irrigation was stopped when most hybrids were in anthesis, but those lines that matured earlier suffered stress at a more advanced phase than those maturing late. However, this difference between the hybrids did not cause significant difference in the hybrids $x$ environments interaction.

The characteristics days to flowering, plant height, and $\mathrm{HI}$ show low coefficients of variation according to Pimentel-Gomes (2009). We found larger differences in grain productivity, weight of 1000 grains, and panicle weight coefficients but these were in the expected range for these characteristics (Table 1). Our results are similar to those reported by Tardin et al. (2013) in a study on drought tolerance in sorghum. The mean temperature during the trial was approximately $25^{\circ} \mathrm{C}$ (Figure 1) and no rain fell during this time.

Grain yield is graphically depicted in Figure 2, in which the x-axis shows yield under stress-free conditions and the y-axis shows the yield under drought stress. The graphic was divided into four quadrants in which the upper left quadrant $(A)$ represents tolerant hybrids that are non-responsive to improvement in the environment, the lower left quadrant (B) represents hybrids susceptible to drought and non-responsive, the lower right quadrant $(C)$ shows hybrids susceptible to drought and responsive, and the upper right quadrant (D) identifies the most promising hybrids, i.e., those that are tolerant and responsive to improvement in the environment. Fifteen hybrids were classified in quadrant D, i.e., gave above average yields in both environments: (1) 1170090, (2) 1169082, (3) 1170092, (4) 1170064, (5) 1167026, (6) 1167064, (7) 1170093, (8) 1167008, (9) 1167029, (10) 1170055, (11) 0009061, (12) 1167092, (13) 1105647, (14) 1170019, and (15) 1168054 (Figure 2). These hybrids yielded an average of 5.41 tonnes/ha for both environments and 4.04 and 6.76 tonnes/ha under drought stress and stress free conditions, respectively. Under drought stress, the selected hybrids yielded one tonne/ha of grains above the average of the trials. 


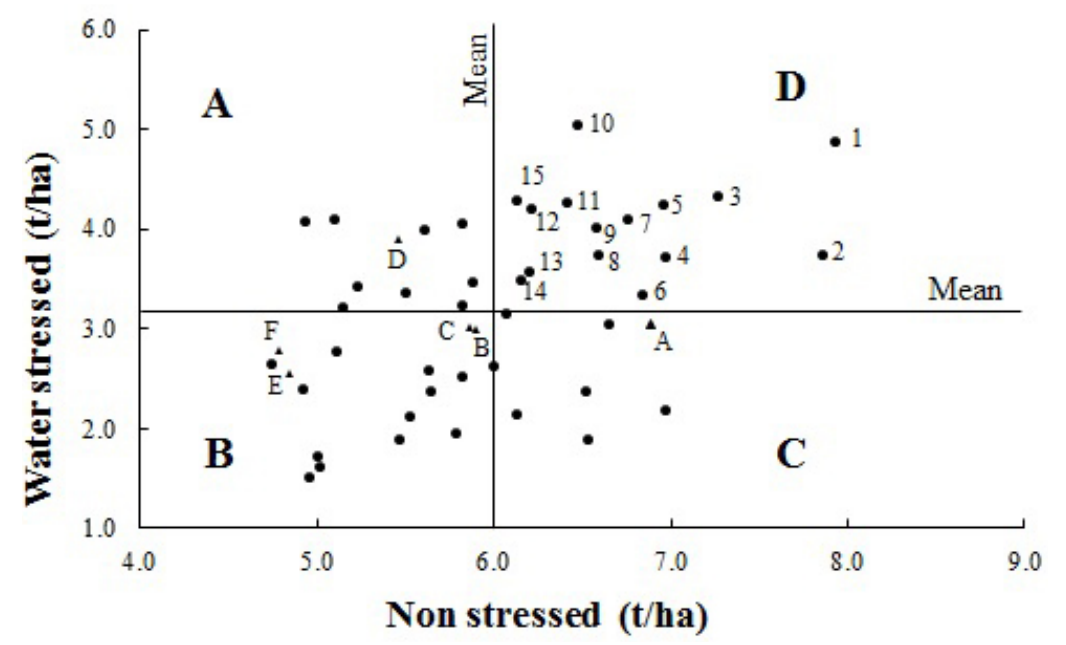

Figure 2. Grain yields of 49 hybrids grown with and without water stress. A. Hybrids with yields above average only in the environment with stress. B. Hybrids with low yields under both water regimes. C. Hybrids with yields above average in the environment without water stress. D. Hybrids with high yields under both water regimes. (1) 1170090; (2) 1169082; (3) 1170092; (4) 1170064; (5) 1167026; (6) 1167064; (7) 1170093; (8) 1167008; (9) 1167029; (10) 1170055; (11) 0009061; (12) 1167092; (13) 1105647; (14) 1170019; (15) 1168054. (A) DKB 550, (B) 1 G282, (C) BRS 332, (D) BRS 310, (E) BRS 304, and (F) BRS 330.

None of the check cultivars gave above average yields in both environments. The hybrid DKB 550 was the highest yielding check cultivar under stress-free conditions, but its performance was poor under drought stress. BRS 310 performed well under drought stress, but was below average in stress-free conditions; it was classified as a tolerant line that was non-responsive to environmental improvement. The $1 \mathrm{G} 282$ and BRS 332 hybrids were closest to the average in the two environments, whereas the BRS 304 and BRS 330 had the lowest yields in the two environments and should not be planted under drought stress conditions (Figure 2).

Sorghum is sensitive to water stress during grain filling and late drought is the most limiting factor for sorghum production worldwide. Our results show a reduction in grain size under drought stress. The Scott \& Knott test for the weight of 1000 grains separated the hybrids into two groups. Ten of 15 hybrids selected for yield were classified in the group of largest grain weight. Usually, more productive hybrids show greater grain weight (Figure 3).

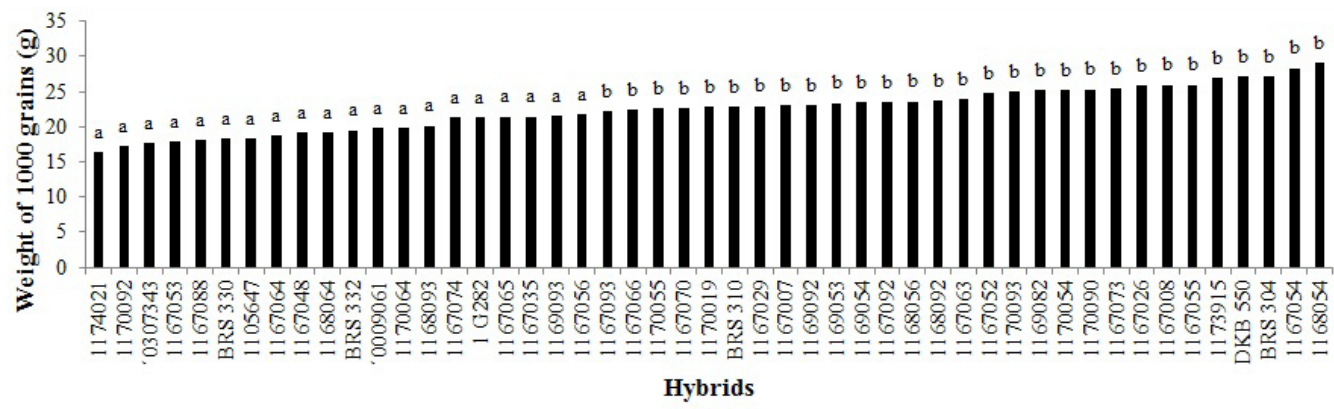

Figure 3. Mean weights of 1000 grains in each of the 49 sorghum hybrids grown with and without water stress. Hybrids followed by the same letter are not statistically different at the $5 \%$ level of probability by a Scott \& Knott test. 
Similar results can be observed in Figure 4, in which all selected hybrids for grain productivity were classified as having larger HIs in both environments, except for hybrid 1168054 . These results show that selection for grain size and highest $\mathrm{HI}$ is an important step in increasing the productivity of sorghum hybrids under post-flowering water stress.

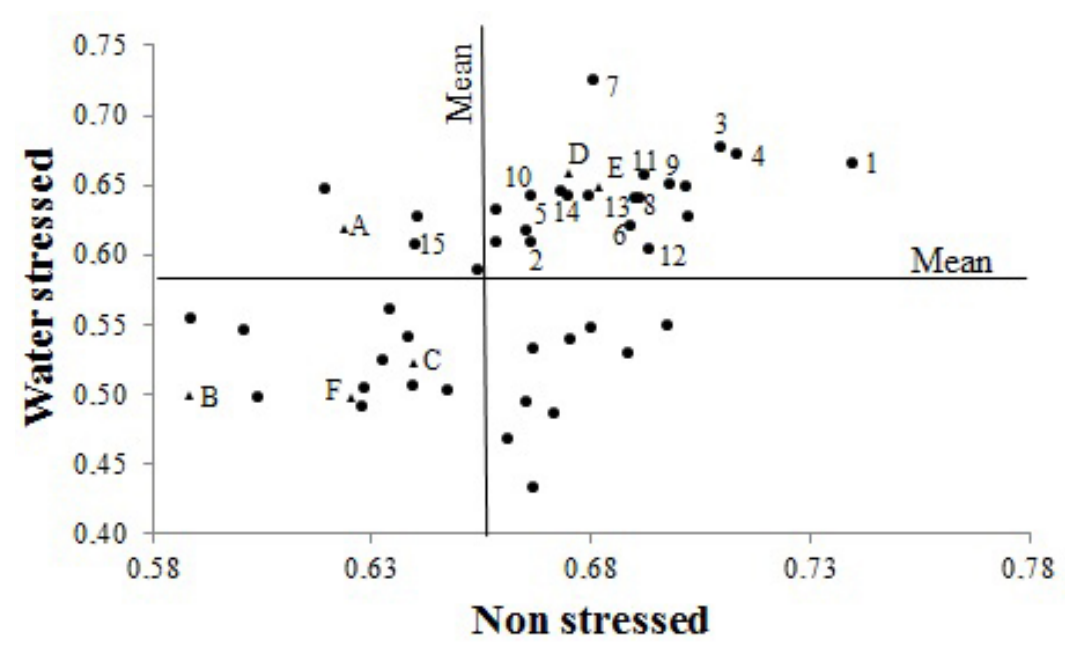

Figure 4. Harvest indexes of 49 hybrids grown with and without water stress. (1) 1170090; (2) 1169082; (3) 1170092; (4) 1170064; (5) 1167026; (6) 1167064; (7) 1170093; (8) 1167008; (9) 1167029; (10) 1170055; (11) 0009061; (12) 1167092; (13) 1105647; (14) 1170019; (15) 1168054. (A) DKB 550, (B) 1 G282, (C) BRS 332, (D) BRS 310, (E) BRS 304, and (F) BRS 330.

Improvements in drought tolerance in sorghum grown in Brazil also requires the selection of earlier maturing hybrids as sorghum is cultivated as a second crop and the period of greatest risk of water stress is at the end of the season. Earlier maturing hybrids can escape the stress by earlier grain filling. Analysis of the days to flowering characteristic separated the hybrids into eleven groups. All hybrids bloomed before 70 days after sowing and no late hybrids were found (Figure 5). Several hybrid lines flowered earlier than the check cultivars, for example, 1168054, 1170054, and 1167054 flowered earlier than 61 days. Among hybrids selected for grain productivity, the earliest flowering were 1168054, 1170055, 1169082, and 0009061, while the latest were 117019, 1167092,1167026 , and 1170092 . There is a positive correlation between productivity and maturity in grain sorghum. Generally late maturing hybrids are more productive. However to minimize the risk of water stress, late maturing hybrids are recommended for planting only at the beginning of the season and earlier maturing hybrids are preferred for later sowing.

The plant height of cultivars and hybrid of grain sorghum must be between 100 and 150 $\mathrm{cm}$ as the crop is usually harvested using corn or soybean harvesting machines that operate in this range. Furthermore, heights exceeding $150 \mathrm{~cm}$ can result in an increase in falling plants, causing losses during harvesting. In the present study, only hybrids 1167055, 1170054, 1168054, 1170055, and 1169082 exceeded the preferred range (Figure 5).

Several hybrid lines outperformed the check cultivars for yield in both environments, indicating that it is possible to obtain hybrids that are more drought-tolerant and also responsive to environmental improvement. Such hybrids would reduce production losses in second-season 
crops and thus ensure greater profitability to the sorghum grower during seasons of drought stress.
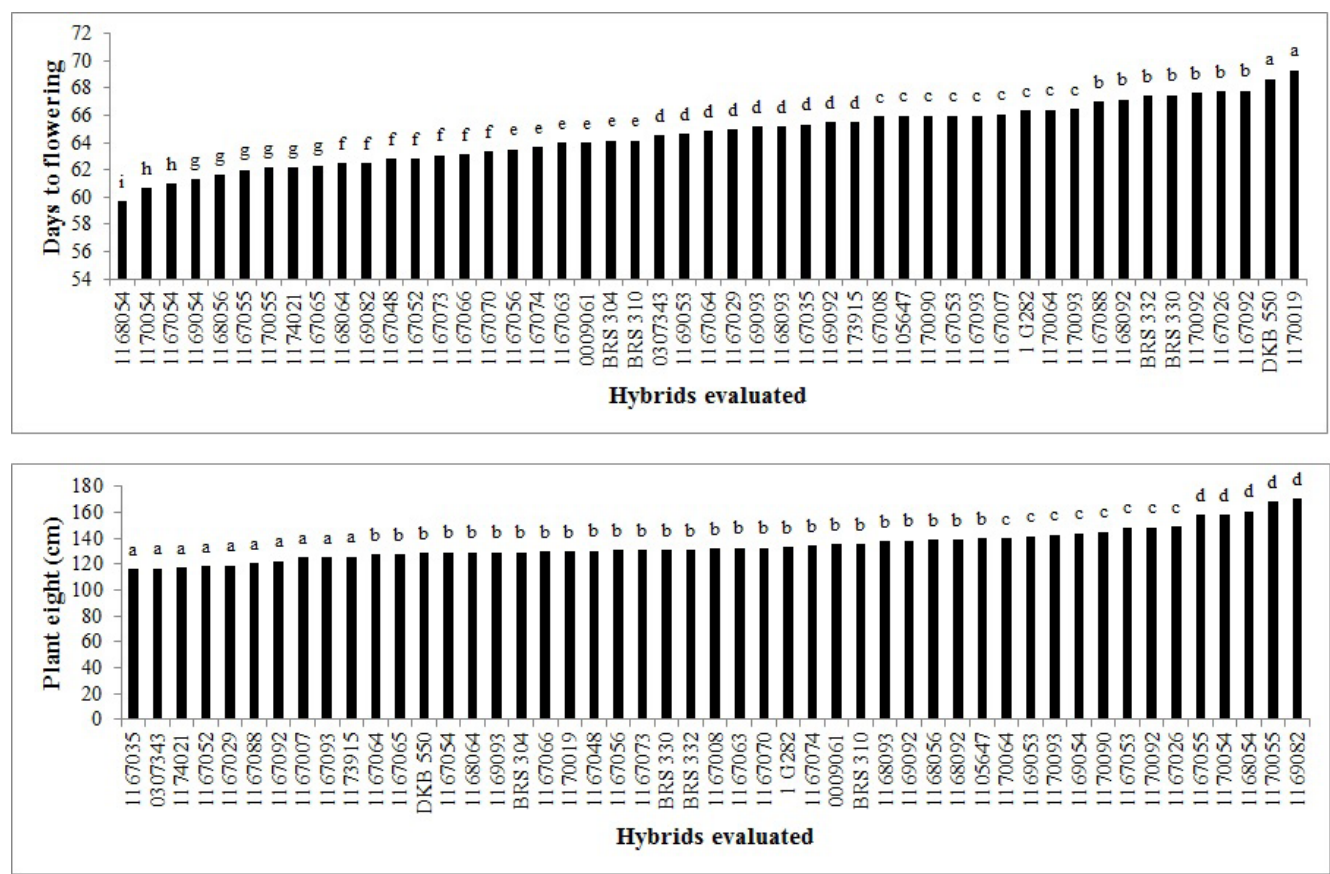

Figure 5. Mean of days to flowering and of plant height in the 49 sorghum hybrids grown with and without water stress. Hybrids followed by the same letter are not statistically different at the $5 \%$ level of probability by a Scott \& Knott test.

\section{CONCLUSION}

Although sorghum is a drought-tolerant crop, it can still suffer yield reduction when grown under drought conditions. Exposure of hybrid lines to water stress generally reduced the grain yield, but also enabled the selection of drought tolerant hybrids that gave smaller reductions in yield under stress conditions.

The hybrids 1170090, 1170092, 1170064, 1167026, 1167064, 1170093, 1167008, 1167029, 0009061, 1167092, 1105647, and 1170019 were drought-tolerant and responsive to improvements in the environment. The hybrids 1168054, 1170055, and 1169082 were also drought-tolerant and responsive to environmental improvement; however, they had an average plant height above $150 \mathrm{~cm}$ and are not recommended. The most productive hybrids had bigger grains and a larger $\mathrm{HI}$.

\section{Conflicts of interest}

The authors declare no conflict of interest.

\section{ACKNOWLEDGMENTS}

Research supported by Embrapa Milho e Sorgo, Fundação de Amparo à Pesquisa do Estado de Minas Gerais (FAPEMIG), Conselho Nacional de Desenvolvimento Científico e 
Tecnológico (CNPq), and Banco do Nordeste do Brasil (BNB).

\section{REFERENCES}

Borrell AK, Mullet JE, George-Jaeggli B, van Oosterom EJ, et al. (2014). Drought adaptation of stay-green cereals is associated with canopy development, leaf anatomy, root growth, and water uptake. J. Exp. Bot. 65: 6251-6263.

CONAB (Companhia Nacional de Abastecimento) (2015). Acompanhamento de safra brasileira: grãos, quinto levantamento, outubro 2014/Companhia Nacional de Abastecimento. Conab, Brasília.

Cruz CD (2006). Programa Genes: Biometria. Editora UFV, Viçosa.

IPCC (2012). Managing the risks of extreme events and disasters to advance climate change adaptation. A Special Report of Working Groups I and II of the Intergovernmental Panel on Climate Change. (Field CB, Barros V, Stocker TF, Qin D, et al., eds.). Cambridge University Press, Cambridge and New York.

Magalhães PC, Durães FOM and Rodrigues JAS (2003). Fisiologia da planta de sorgo. (Comunicado técnico n 86 ) EMBRAPA Milho e Sorgo, Sete Lagoas.

Manjarrez-Sandoval P, Gonzalez-Hernandez VA, Mendoza-Onofre LE and Engleman EM (1989). Drought stress effects on the grain yield and panicle development of sorghum. Can. J. Plant Sci. 69: 631-641.

Menezes CB, Ticona-Benavente CA, Tardin FD, Cardoso MJ, et al. (2014). Selection indices to identify drought-tolerant grain sorghum cultivars. Genet. Mol. Res. 13: 9817-9827.

Mutava RN, Prasad PVV, Tuinstra MR, Kofoid KD, et al. (2011). Characterization of sorghum genotypes for traits related to drought tolerance. Field Crops Res. 123: 10-18.

PBMC (2013). Executive Summary: Impacts, Vulnerability and Adaptation. Contribution of Working Group 2 to the First Assessment Report of the Painel Brasileiro de Mudanças Climáticas (PBMC). (Assad ED and Magalhães AR, eds.). COPPE. Universidade Federal do Rio de Janeiro, Rio de Janeiro.

Pimentel-Gomes F (2009). Curso de estatística experimental. 15th edn. FEALQ, Piracicaba.

Reddy BVS, Ashok Kumar A, Ramesh S and Reddy PS (2011). Sorghum genetic enhancement for climate change adaptation. In: Crop Adaptation to Climate Change. 1st edn. (Yadav SS, Redden RJ, Hatfield JL, Lotze-Campen H, et al., eds.). Wiley-Blackwell, Oxford.

Rosenow DT, Ejeta G, Clark LE, Gilbert ML, et al. (1996). Breeding for pre- and post-flowering drought stress resistance in sorghum. In: Proceedings of the international conference on genetic improvement of sorghum and millet. (Rosenow DT, ed.). Lubbock, 400-424.

Tardin FD, Almeida Filho JE, Oliveira CM, Leite CEP, et al. (2013). Avaliação agronômica de híbridos de sorgo granífero cultivados sob irrigação e estresse hídrico. Rev. Bras. Milho Sorgo 12: 102-117.

Tolk JA, Howell TA and Miller FR (2013). Yield component analysis of grain sorghum grown under water stress. Field Crops Res. 145: 44-51. 